\title{
OPTIMALISASI WEBSITE UNIT BISNIS MENGGUNAKAN PENDEKATAN BUSINESS MODEL CANVAS
}

\author{
${ }^{1}$ Ayutyas Sayekti, ${ }^{2}$ Naila Syifa \\ 1,2Sekolah Vokasi Institut Pertanian Bogor, Bogor, Indonesia \\ Email korespondensi: ${ }^{1}$ ayutyassa@apps.ipb.ac.id
}

\begin{abstract}
ABSTRAK
Tujuan dari penelitian ini adalah merumuskan ide bisnis berupa strategi optimalisasi website unit bisnis Salamah Aqiqah di CV Mitra Tani Farm serta menganalisis kelayakan rencana pengembangan bisnis secara finansial dan nonfinansial. Subjek penelitian ini adalah unit Salamah Aqiqah milik CV Mitra Tani Farm. Data penelitian berupa data primer dan sekunder. Pengumpulan data primer melalui wawancara mendalam dan data sekunder dikumpulkan dari laporan keuangan Salamah Aqiqah. Metode analisis data menggunakan analisis kualitatif berupa analisis finansial dan nonfinansial. Analisis finansial menggunakan analisis laba rugi dan R/C ratio, sedangkan analisis nonfinansial menggunakan business model canvas dan analisis SWOT. Hasil penerapan ini mengubah komponen elemen model bisnis, seperti adanya pengurangan agent marketing pada elemen channels, serta adanya penambahan komponen pada elemen customer segment, value proposition, customer relationships, key activities, key resources, key partners, revenue streams, dan cost structure. Berdasarkan hasil analisis nonfinansial sembilan elemen model bisnis pada pengembangan bisnis ini layak dilakukan.
\end{abstract}

Kata Kunci: analisis SWOT; business model canvas; search engine optimization; teknologi informasi

\section{ABSTRACT}

The purpose of this study is to formulate a business idea in the form of a website optimization strategy for the Salamah Aqiqah business unit at CV Mitra Tani Farm and analyze the feasibility of a financial and non-financial business development plan. The subject of this research is the CV Mitra Tani Farm business unit owned by CV MItra Tani Farm. Research data in the form of primary and secondary data. Primary data was collected through in-depth interviews and secondary data was collected from Salamah Aqiqah's financial statements. The data analysis method used qualitative analysis in the form of financial and non-financial analysis. Financial analysis uses profit and loss analysis and R/C ratio, while non-financial analysis uses business model canvas and SWOT analysis. The results of this application change the components of the business model elements, such as the reduction of marketing agents in the channels element, and the addition of components to the customer segment, value proposition, customer relationships, key activities, key resources, key partners, revenue streams and cost structure elements. Based on the results of the non-financial analysis, the nine elements of the business model in developing this business are feasible.

Keywords: business model canvas; information technology; search engine optimization; SWOT analysis

\section{KETERANGAN ARTIKEL}

Riwayat Artikel: diterima: 11 Oktober 2021; direvisi: 20 November 2021; disetujui: 24 Desember 2021

Klasifikasi JEL: L86, M21

Cara mensitasi: Sayekti, A., \& Syifa, N. (2021). Optimalisasi Website Unit Bisnis Menggunakan Pendekatan Business Model Canvas. JIMFE (Jurnal IImiah Manajemen Fakultas Ekonomi), 7(2), $255-270$. https://doi.org/10.34203/jimfe.v7i2.4044 


\section{PENDAHULUAN}

Perkembangan teknologi informasi dan komunikasi yang pesat saat ini menyebabkan mulai muncul berbagai platform bisnis berbasis internet. Pengaruh perkembangan teknologi tersebut menyebabkan dunia pemasaran dituntut untuk menawarkan sebuah konsep pemasaran baru melalui jaringan internet yang disebut dengan istilah digital marketing/e-marketing. Menurut Stokes (2013), digital marketing mendorong penciptaan permintaan menggunakan internet dan memenuhi permintaan dengan caracara baru dan inovatif. Berdasarkan laporan digital periode Januari 2020 yang dilansir oleh Firdaaus, (2020) populasi pengakses internet di Indonesia mencapai sekitar 175,4 juta pengguna, jumlah tersebut sebesar $64 \%$ dari populasi penduduk Indonesia yang mencapai 272,1 juta jiwa. Penetrasi pengguna internet di Indonesia per bulan Januari 2020 bertambah sebesar $17 \%$ dari tahun sebelumnya. Angka tersebut menunjukan penetrasi penggunaan internet di Indonesia cukup besar.

Pengguna internet saat ini memanfaatkan internet untuk berbagai macam aktivitas, salah satunya adalah aktivitas berbelanja online/e-commerce. Menurut Nurmalina dkk. (2015), e-commerce adalah bagian dari digital marketing, yaitu pembelian dan penjualan barang dan jasa di internet atau dikenal dengan istilah online marketing. Berdasarkan data yang didapat dari statista digital market outlook for fintech, aktivitas e-commerce di Indonesia Januari 2020 sebanyak 93\% dari populasi di Indonesia melakukan pencarian produk/jasa untuk dibeli secara online, aktivitas pencarian tersebut dilakukan melalui mesin pencari seperti Google, Bing, Yahoo, dan mesin pencari lainnya di sebuah platform. Penting untuk suatu usaha mengembangkan bisnisnya dengan memulai dari sebuah website karena besar kemungkinan calon konsumen mencari sesuatu yang akan dibeli melalui website.

Teknologi yang semakin maju seiring dengan kebutuhan akan pelayananan untuk memuaskan konsumen dan melengkapi aplikasi di dalam suatu usaha maka adanya $e$-business sangat membantu. $E$ commerce adalah kegiatan perdagangan yang dilakukan melalui perantara halaman web di internet, $e$ commerce memiliki kelebihan dibandingkan dengan perdagangan biasa seperti kemudahan dan fleksibilitas yang ditawarkan. E-commerce merupakan hasil penerapan aplikasi teknologi informasi, yang memungkinkan terjadinya transaksi antara produsen dan konsumen melalui internet (Fatimah, 2017). Aktivitas e-commerce yang tinggi dapat terjadi karena muncul berbagai platform yang menjual berbagai kebutuhan sehari-hari konsumen, bahkan dengan penawaran menarik seperti gratis ongkos kirim serta kemudahan dalam pemesanan karena dapat dilakukan dimana saja dan kapan saja, pembayaran dapat dilakukan secara tunai atau non tunai bahkan ada yang menerapkan sistem cash on delivery (COD). Adanya peningkatan penetrasi pengguna internet dan aktivitas e-commerce yang tinggi memberikan peluang bagi suatu perusahaan produk/jasa untuk mengembangkan usahanya melalui internet (Cizmeci \& Ercan, 2015 dan Bilgin, 2018). Setiap bisnis saat ini khususnya kuliner tidak lepas dari yang namanya strategi pemasaran yang bertujuan untuk memasarkan dan mempromosikan bisnis kulinernya (Handika \& Darma, 2018). Dari uraian diatas, yang paling mendasar sebenarnya dalam pemasaran ialah kepuasan pelanggan. Kepuasan pelanggan (konsumen), menjadi yang utama bagi para pebisnis (Fawaid, 2017).

CV Mitra Tani Farm yang berada di Ciampea Kabupaten Bogor adalah suatu usaha pada subsektor peternakan dengan komoditas utama domba. Usaha ini sudah menerapkan digital marketing, salah satunya adalah pada unit bisnis Salamah Aqiqah dan Catering. Penerapan digital marketing pada usaha tersebut dilakukan karena perusahaan ingin menyesuaikan diri dengan perkembangan pemasaran saat ini yang banyak memanfaatkan internet. Media digital yang digunakan perusahaan dalam penerapan digital marketing adalah media sosial seperti Facebook, Instagram, Youtube, dan website, tetapi dalam pemanfaatan website belum sepenuhnya optimal karena tidak adanya tenaga kerja yang ahli pada bidang tersebut.

Tujuan dalam penelitian ini adalah sebagai berikut: (1) memetakan business model canvas unit bisnis Salamah Aqiqah, CV Mitra Tani dan SWOT, dan (2) menganalisis kelayakan ide pengembangan bisnis melalui analisis secara finansial dan analisis nonfinansial untuk optimalisasi pada website Salamah 
Aqiqah dengan penerapan search engine optimization (SEO) dengan tujuan meningkatkan peringkat website pada hasil pencarian mesin pencari. Peningkatan peringkat website salamah Aqiqah sangat dibutuhkan terutama di era new normal untuk menarik konsumen agar mengunjungi, tertarik dan melakukan pembelian produk, selain itu masih kurangnya riset mengenai analisis kelayakan pengembangan bisnis dengan penerapan SEO sehingga masih diperlukan bagi dunia bisnis.

\section{KAJIAN LITERATUR}

\section{Business Model Canvas dan Analisis SWOT}

Business model canvas (BMC) adalah sebuah model bisnis yang menggambarkan dasar pemikiran tentang bagaimana organisasi menciptakan, memberikan, dan menangkap nilai (Osterwalder \& Pigneur 2010). BMC merupakan salah satu konsep model bisnis dapat menjelaskan secara sederhana bagaimana suatu perusahaan dapat menghasilkan profit melalui sembilan elemen yang terbagi menjadi beberapa fokus. Terdapat sembilan elemen dalam BMC, yaitu: customer segment, value proposition, channels, customer relationship, key resources, key activities, key partnership, revenue stream, cost structure.

Analisis SWOT adalah identifikasi berbagai faktor secara sistematis untuk merumuskan strategi perusahaan. Faktor yang diidentifikasi adalah lingkungan internal dan eksternal berupa kekuatan, kelemahan, peluang dan ancaman. Analisis ini didasarkan pada logika yang dapat memaksimalkan kekuatan (strength) dan peluang (opportunity), tetapi secara bersamaan dapat meminimalkan kelemahan (weakness) dan ancaman (threat) (Rangkuti, 2015). Identifikasi faktor internal dan faktor eksternal perusahaan dari setiap elemen business model canvas.

Menurut Osterwalder \& Pigneur (2010), menilai integritas keseluruhan model bisnis sangat penting, cara efektif untuk melakukannya adalah mengkombinasikan analisis kekuatan, kelemahan, peluang, dan ancaman (SWOT) dengan business model canvas. Analisis SWOT menyediakan empat perspektif untuk menilai elemen-elemen model bisnis, sementara business model canvas menyediakan fokus yang diperlukan untuk diskusi terstruktur (Osterwalder \& Pigneur 2010). Analisis SWOT dilakukan pada setiap elemen business model canvas dengan tujuan menyempurnakan model bisnis yang ada saat ini.

\section{Aspek Keuangan}

Menurut Kasmir \& Jakfar (2003), aspek keuangan merupakan aspek yang digunakan untuk menilai keuangan perusahaan secara keseluruhan. Alat analisis keuangan untuk membantu perusahaan yang akan melakukan pengembangan usaha dapat menggunakan neraca dan laporan laba/rugi. Pada kajian pengembangan bisnis ini dilakukan analisis pada laporan keuangan perusahaan berupa laporan laba/rugi, selain laporan laba/rugi penulis juga menggunakan analisis $\mathrm{R} / \mathrm{C}$ ratio. Perencanaan finansial perusahaan dapat diukur melalui biaya operasional dan laba/rugi. Biaya operasional termasuk biaya produksi, pemeliharaan, dan lainnya yang menggambarkan pengeluaran untuk menghasilkan produksi yang digunakan bagi setiap proses produksi dalam satu periode kegiatan produksi (Nurmalina dkk. 2014). Biaya operasional terdiri dari dua komponen utama, yaitu biaya variabel dan biaya tetap. Biaya variabel adalah biaya yang dikeluarkan untuk menghasilkan output sehingga besar kecilnya selaras dengan perkembangan produksi. Biaya tetap adalah biaya yang tetap dikeluarkan walaupun suatu usaha sedang tidak melakukan kegiatan produksi.

Laporan laba/rugi merupakan laporan keuangan yang menggambarkan hasil usaha dalam suatu periode tertentu. Pada kajian pengembangan bisnis ini dilakukan proyeksi laporan laba/rugi yang menggambarkan besarnya pendapatan yang diperoleh pada suatu periode ke periode berikutnya, dari laporan ini dapat terlihat kondisi keuangan perusahaan apakah terdapat keuntungan atau kerugian 
dalam suatu periode atau beberapa periode (Kasmir \& Jakfar, 2003). Laporan laba rugi terdiri dari total revenue (TR), total fixed cost (TFC), total variabel cost (TVC), total cost (TC), laba bersih sebelum pajak, pajak, dan laba bersih setelah pajak (Nurmalina dkk. 2014).

Analisis $\mathrm{R} / \mathrm{C}$ ratio digunakan untuk menilai efisiensi suatu usaha dengan melakukan perbandingan antara penerimaan dan pengeluaran yang diperoleh. Analisis R/C Ratio dapat dihitung dengan menggunakan rumus berikut.

$$
\frac{R}{C} \text { ratio }=\frac{\text { total revenue }}{\text { total cost }}
$$

Jika nilai $\mathrm{R} / \mathrm{C}$ ratio $>1$ maka usaha yang dijalankan oleh perusahaan dikatakan efisien, $\mathrm{R} / \mathrm{C}$ ratio = 1 usaha yang dijalankan berada pada titik impas, $\mathrm{R} / \mathrm{C}$ ratio $<1$ maka usaha yang dijalankan tidak efisien dan mengalami kerugian.

\section{METODE PENELITIAN}

Penelitian ini adalah penelitian kualitatif dengan pendekatan deskriptif. Penelitian dilakukan pada unit bisnis CV Mitra Tani Farm, yaitu Salamah Aqiqah yang terletak di Jalan Baru Manunggal 51 No. 39 RT 04/ RW 05, Tegalwaru Kecamatan Ciampea, Kabupaten Bogor, Jawa Barat. Data penelitian berupa data primer dan data sekunder. Pengumpulan data primer dilakukan dengan wawancara, diskusi, atau bertanya langsung kepada pemilik perusahaan, serta pihak-pihak terkait dengan perusahaan. Pengumpulan data sekunder berupa laporan keuangan dari Salamah Aqiqah. Metode analisis yang digunakan dalam kajian pengembangan bisnis ini dengan merancang business model canvas, lalu dilakukan evaluasi model bisnis dengan menggunakan analisis SWOT (strength, weakness, opportunity, threat) untuk menyempurnakan model bisnis yang sudah ada. Selain itu, untuk menilai dan mengetahui aspek finansial dari ide pengembangan bisnis berupa proyeksi laporan laba rugi dan $\mathrm{R} / \mathrm{C}$ ratio.

Strategi yang didapatkan penulis berdasarkan analisis SWOT pada model bisnis, menghasilkan suatu ide bisnis yaitu optimalisasi website pada unit bisnis Salamah Aqiqah pada CV Mitra Tani Farm. Skema ide pengembangan bisnis dapat dilihat pada Gambar 1. Kerangka rancangan business model canvas dilakukan untuk optimalisasi website merupakan bagian dari proses pemasaran yang perlu diperhatikan. 


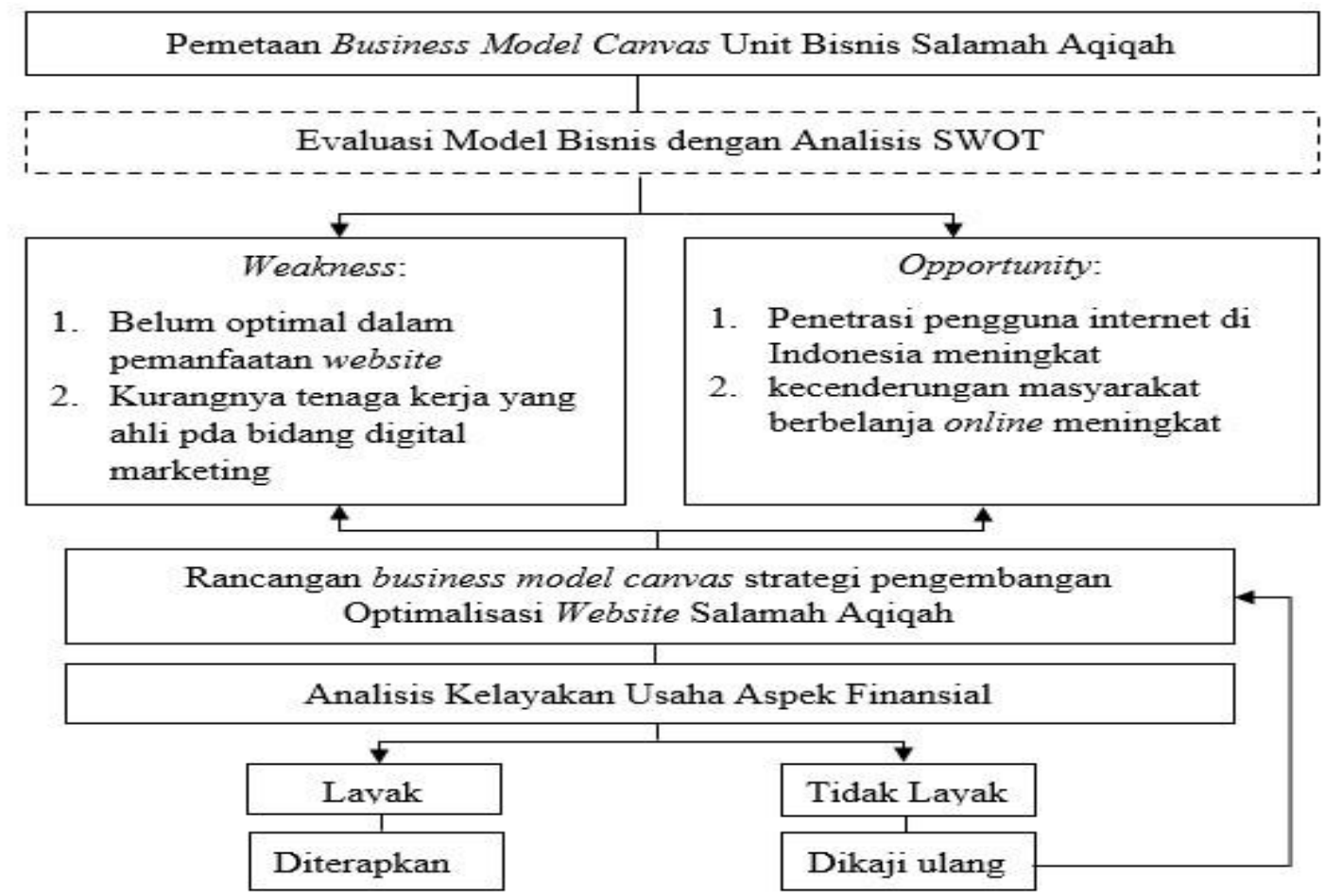

\section{Gambar 1. Kerangka Optimalisasi Webiste Unit Bisnis Salamah Aqiqah dengan BMC pada CV Mitra Tani Farm}

\section{HASIL DAN PEMBAHASAN}

\section{Informasi Subjek Penelitian}

CV Mitra Tani Farm (MT Farm) merupakan usaha yang bergerak di bidang peternakan, khususnya komoditas domba, kambing dan sapi. CV Mitra Tani Farm dirintis pada tahun 2002 oleh Budi Susilo Setiawan, S.Pt., Amrul Lubis, S.Pt., M Afnan Wasom, S.Pt., dan Bahrudin, S.Pt. Pada tahun 2004 usaha ini diresmikan menjadi usaha berbadan hukum. Pada tahun tersebut ada seorang investor yang bernama Drs. Muhtadi, beliau memberikan modal pertama dengan sejumlah uang, modal tersebut digunakan untuk membeli lahan, sarana dan prasarana kandang beserta perlengkapan lainnya dan alat penunjang. Wabah Covid-19 yang terjadi di Indonesia memaksa masyarakat untuk melakukan social distancing salah satunya dengan cara penerapan work from home (WFH) oleh pemerintah tujuannya untuk memutus rantai penyebaran virus. Masyarakat dituntut untuk bergantung pada internet, sehingga penggunaan internet di rumah meningkat untuk melakukan rutinitas baik untuk pekerjaan, pendidikan, maupun berbelanja kebutuhan sehari-hari. Dampak Covid-19 terhadap CV Mitra Tani Farm terutama pada unit binis olahan makanan kaleng meningkat sebesar tiga kali lipat, hal tersebut ditujukkan dengan permintaan yang biasanya hanya seribu kaleng/bulan meningkat menjadi tiga ribu kaleng/bulan.

Sumber daya fisik yang memiliki peran dan fungsi penting dalam suatu perusahaan sebagai sebagai sarana pendukung dalam pelaksanaan kegiatan produksi. CV Mitra Tani Farm memiliki sarana dan prasarana untuk menunjang kegiatan usahanya. Sarana dan prasarana yang dimiliki adalah Lahan seluas $2.056 \mathrm{~m}^{2}$ yang digunakan untuk membangun bangunan utama seperti kandang domba atau kambing dan sapi, rumah potong hewan, tempat penyimpanan pakan, tempat pengolahan pakan, kantor, gudang penyimpanan, area parkir, kamar mandi, dapur masak dan mess karyawan. Sumber daya 
yang dimiliki selain lahan adalah mesin, alat transportasi, peralatan kendang, dan penunjang untuk bisnis.

Sumber daya manusia merupakan salah satu input terpenting dalam proses produksi di suatu perusahaan. Sumber daya manusia yang dimiliki oleh CV Mitra Tani Farm berjumlah 28 yang terbagi ke dalam tiga bagian, yaitu bagian kandang, produksi, dan pemasaran. Modal yang diperoleh oleh CV MT Farm adalah modal dari investor yang bernama Drs. Muhtadi. Beliau memberikan modal pertama dengan sejumlah uang sebesar Rp100.000.000,00. Modal tersebut digunakan untuk membeli lahan, sarana dan prasarana kandang beserta perlengkapan lainnya, dan alat penunjang. Kesepakatan antara CV Mitra Tani Farm dengan investor pada saat itu adalah dengan cara bagi hasil, 30\% untuk investor dan 70\% untuk CV Mitra Tani Farm. CV Mitra Tani Farm memiliki visi dan misi agar perusahaan berjalan sesuai arah dan tujuan yang ingin dicapai. Berikut adalah visi dan misi dari CV Mitra Tani Farm. Terdapat beberapa kekuatan dan kelemahan yang dimiliki oleh perusahaan CV Mitra Tani Farm berdasarkan analisis internal perusahaan.

Tabel 1. Kekuatan dan Kelemahan Pada Perusahaan CV Mitra Tani Farm

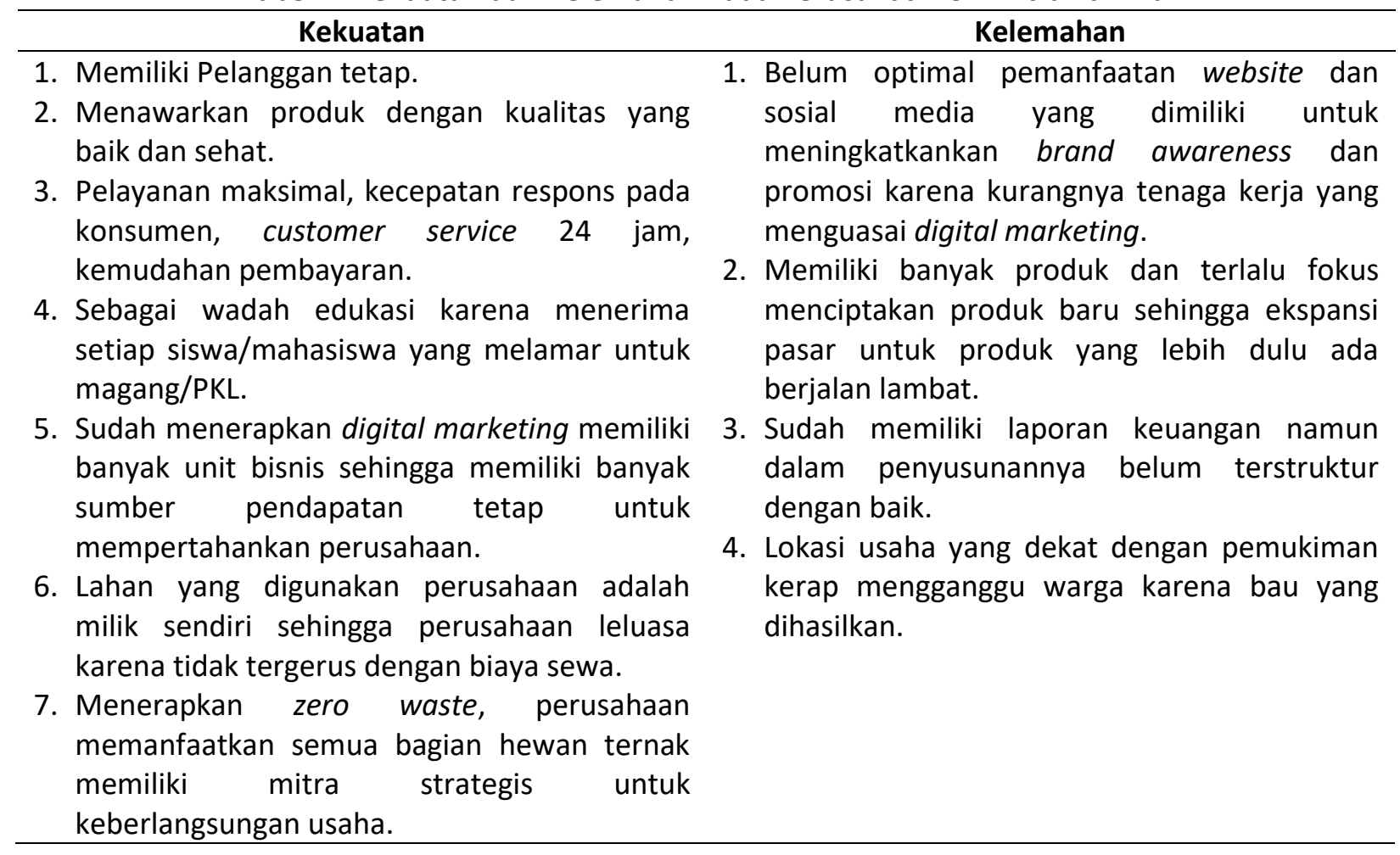

\section{Pemetaan Business Model Canvas di Unit Bisnis Salamah Aqiqah}

Pemetaan dilakukan untuk mengidentifikasi sembilan elemen pada model bisnis unit bisnis Salamah Aqiqah dan Catering. Berikut sembilan elemen Business Model Canvas yang telah dipenuhi oleh unit bisnis Salamah Aqiqah dan Catering.

Pertama, customer segments dengan mengelompokkan pelanggan ke dalam segmen yang berbeda dengan kebutuhan umum, perilaku umum, atau atribut lainnya. Output pada elemen ini adalah menghasilkan target konsumen yang lebih terfokus dan detail sehingga akan lebih mudah dimengerti. Berdasarkan geografis hanya di wilayah Jabodetabek dengan demografis semua kalangan usia dan tingkat ekonomi kalangan menengah keatas dengan psikografis gaya hidup yang praktis. Target 
konsumen pada unit bisnis Salamah Aqiqah dan Catering adalah keluarga muslim yang membutuhkan jasa aqiqah dan masyarakat/organisasi yang membutuhkan jasa catering dengan gaya hidup praktis.

Kedua, value proposition yang merupakan hasil dari kinerja gabungan antara produk yang ditawarkan dan pelayanan yang diberikan pada segmen pelanggan yang spesifik. Nilai yang ditawarkan Salamah Aqiqah kepada pelanggan adalah hewan yang berkualitas dengan pembayaran yang dapat dicicil, kemudahan akses informasi, edukatif dan informatif, memiliki olahan kaleng, fleksibel sesuai dengan keinginan konsumen serta gratis ongkos kirim khusus pelanggan Jabodetabek dan mendapatkan buku risalah serta video dokumentasi.

Ketiga, channels yang merupakan saluran pemasaran langsung dan tidak langsung. Untuk saluran pemasaran langsung Salamah Aqiqah menawarkan secara langsung kepada konsumen yang berkunjung ke CV Mitra Tani Farm dan memanfaatkan word of mouth. Saluran pemasaran tidak langsung dilakukan melalui agent marketing yang diupah Rp50.000,00 per ekor yang berhasil dijual dan media internet dengan memanfaatkan platform yang banyak digunakan oleh masyarakat, yaitu Instagram, Facebook, dan Whatsapp. Berdasarkan fasenya, saluran pemasaran unit bisnis Salamah Aqiqah terdiri dari lima fase, yaitu awareness, evaluation, purchase, delivery dan after sales.

Keempat, customer relationship untuk menjalin hubungan dengan konsumen. Karyawan bagian administrasi merangkap customer service dituntut untuk selalu ramah dan cepat tanggap dalam melayani konsumen, pelayanan customer service yang diberikan perusahaan adalah 24 jam. Salamah Aqiqah juga selalu menyimpan nomor Whatsapp konsumen yang beraqiqah untuk mem-follow up konsumen dan untuk mengirimkan video dokumentasi pemotongan hewan aqiqah.

Kelima, adalah revenue streams yang merupakan hasil penjualan aqiqah dan catering. Aqiqah dan catering memiliki banyak pilihan paket aqiqah dengan variasi harga. Penjualan aqiqah paling banyak adalah dari Paket Aqiqah A1 jantan dugul untuk anak perempuan dan Paket Aqiqah A2 jantan dugul untuk anak laki-laki. Paket Aqiqah A1 untuk perempuan dan Paket Aqiqah A2 untuk laki-laki memiliki perbedaan dari jumlah dombanya, Paket Aqiqah A1 berjumlah satu ekor domba yang memiliki bobot antara $14 \mathrm{~kg}-15 \mathrm{~kg}$, sedangkan Paket Aqiqah A2 berjumlah dua ekor dengan bobot yang sama dengan Paket Aqiqah A1.

Keenam, key resources yang merupakan sumber daya yang dimiliki perusahaan untuk melaksanakan kegiatan usaha adalah sumber daya fisik berupa bangunan seperti kantor, dapur masak, kandang, kendaraan, dan peralatan. Kendaraan untuk mendukung kegiatan operasional usaha adalah mobil untuk mengantarkan pesanan aqiqah, mobil pick up untuk mengangkut pakan ternak seperti ampas tahu dan rumput, dan sepeda motor untuk mobilisasi pegawai dalam kegiatan operasional usaha. Sumber daya manusia pada unit bisnis ini adalah berjumlah 28 karyawan. Sumber daya finansial adalah dana yang digunakan untuk membangun usaha, dana usaha CV Mitra Tani Farm berasal dari pemilik usaha dan investor.

Ketujuh, key activities yang sebagai salah satu unit bisnis yang memiliki kontribusi pendapatan cukup besar, Salamah Aqiqah tentunya melewati tahapan proses produksi dan pemasaran. Proses produksi tersebut terbagi menjadi dua, yaitu proses produksi untuk catering dan aqiqah. Dalam pemasarannya Salamah Aqiqah menerapkan sistem pemasaran langsung dan tidak langsung.

Kedelapan, key partners yang menjelaskan jaringan pemasok dan mitra yang membuat model bisnis berfungsi. Mitra pada usaha ini adalah pemasok bahan baku untuk aqiqah/katering dan pengalengan. Untuk penggemukan domba/kambing dan sapi dari peternak yang berada di Pula Jawa dan Lampung, untuk bahan baku aqiqah dan katering seperti beras organik dari Jawa Tengah. Bahan baku dari penjual sayur terdekat dan untuk kemasan kaleng bekerjasama dengan PT ICMP. 
Kesembilan, cost structure adalah biaya investasi, variabel, dan tetap. Biaya investasi berupa kandang, kendaraan operasional, mesin dan peralatan-peralatan yang memiliki umur ekonomis, seperti komputer, printer, freezer, kamera, dan lainnya.

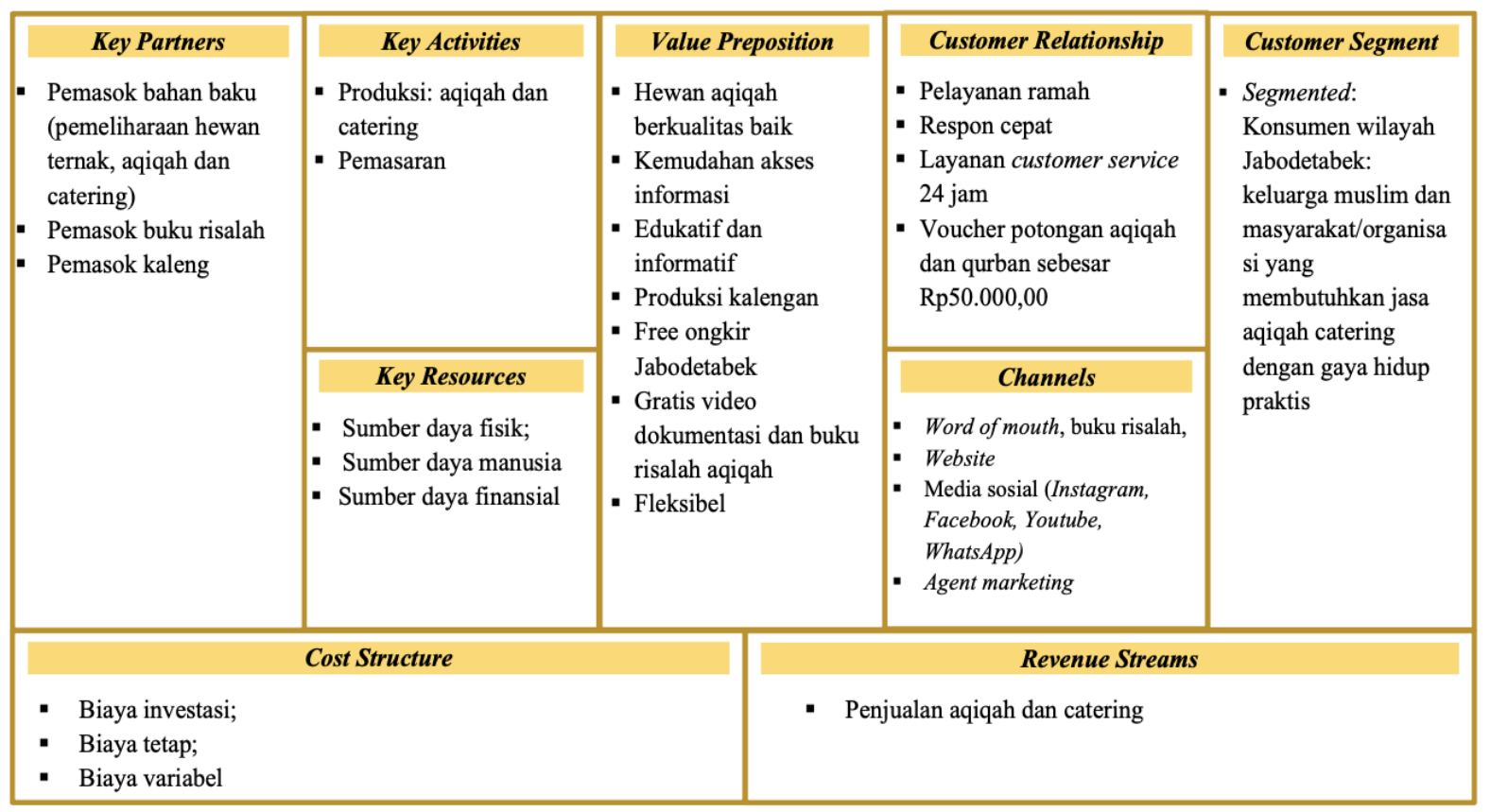

Gambar 2. Business Model Canvas Unit Bisnis Salamah Aqiqah Sebelum Pengembangan

\section{Evaluasi Business Model Canvas dengan Analisis SWOT}

Untuk menyempurnakan model bisnis agar lebih relevan dengan kondisi perusahaan, perlu dilakukannya evaluasi model bisnis pada setiap elemen business model canvas. Evaluasi dilakukan dengan melakukan analisis SWOT terhadap setiap elemen business model canvas, tahap selanjutnya dibuat matriks SWOT untuk memudahkan pengambilan keputusan dalam pengembangan ide bisnis dengan pilihan empat formulasi strategi. 


\begin{tabular}{|c|c|c|}
\hline Internal & \begin{tabular}{ll}
\multicolumn{2}{l}{ Kekuatan (strength) } \\
1. & Pelanggan selalu ada khusus wilayah \\
& Jabodetabek \\
2. & Hewan aqiqah yang berkualitas \\
3. & Kemudahan akses informasi \\
4. & Edukatif \\
5. & Aqiqah dikemas kaleng \\
6. & Penerapan digital marketing \\
7. & Free ongkir Jabodetabek \\
8. & Pelayanan ramah 24 jam \\
9. & Pendapatan yang kontinyu dari aqiqah \\
10. & Hubungan baik dengan mitra/pemasok
\end{tabular} & $\begin{array}{l}\text { Kelemahan (weakness) } \\
\text { 1. Cakupan segmen belum luas } \\
\text { 2. Pemanfaatan website yang belum optimal } \\
\text { 3. Informasi yang disampaikan tidak cukup detail } \\
\text { 4. Pencatatan arus pendapatan yang belum cukup } \\
\text { terstruktur } \\
\text { 5. Kurang tenaga ahli pada bidang digital marketing } \\
\text { 6. Lokasi produksi dan kantor berdekatan dengan } \\
\text { kandang } \\
\text { 7. Tidak ada mitra yang ahli pada pengembangan } \\
\text { digital marketing } \\
\text { 8. Tidak ada perencanaan alokasi dana }\end{array}$ \\
\hline $\begin{array}{l}\text { Peluang (opportunity) } \\
\text { 1. Bertambah cakupan segmen } \\
\text { 2. Gaya hidup konsumen yang praktis } \\
\text { 3. Belum ada yang menggunakan kemasan kaleng untuk aqiqah } \\
\text { 4. Gaya hidup konsumen serba online } \\
\text { 5. Tidak semua usaha sejenis menerapkan digital marketing } \\
\text { 6. Cakupan komunikasi dan informasi semakin luas } \\
\text { 7. Teknologi yang memudahkan aktivitas agar lebih efektif dan } \\
\text { 8. } \quad \text { Kerja sama dengan mitra yang memiliki jaringan lebih luas }\end{array}$ & 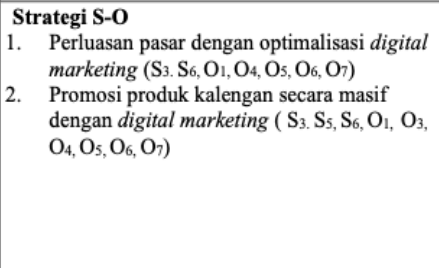 & $\begin{array}{l}\text { Strategi W-O } \\
\text { 1. Optimalisasi website Salamah Aqiqah }\left(\mathrm{W}_{1}, \mathrm{~W}_{2}, \mathrm{~W}_{5} \text {, }\right. \\
\left.\mathrm{W}_{7}, \mathrm{O}_{1}, \mathrm{O}_{2}, \mathrm{O}_{4}, \mathrm{O}_{5}, \mathrm{O}_{6}, \mathrm{O}_{7}\right)\end{array}$ \\
\hline $\begin{array}{l}\text { Ancaman (Threat) } \\
\text { 1. Pelanggan beralih ke perusahaan lain } \\
\text { 2. Keunggulan lain usaha sejenis yang tidak dimiliki perusahaan } \\
\text { 3. Penyalahgunaan internet oleh orang tidak bertanggung jawab } \\
\text { (peretas) } \\
\text { 4. Pelanggaran perjanjian oleh konsumen dan mitra } \\
\text { 5. Adanya penyakit pada hewan ternak } \\
\text { 6. Terjadi inflasi } \\
\text { 7. Fluktuasi harga }\end{array}$ & $\begin{array}{l}\text { Strategi S-T } \\
\text { 1. } \begin{array}{l}\text { Meningkatkan hubungan baik dengan } \\
\text { pelanggan }\left(\mathrm{S}_{1}, \mathrm{~S}_{8}, \mathrm{~T}_{1}, \mathrm{~T}_{4}\right)\end{array}\end{array}$ & $\begin{array}{l}\text { Strategi W-T } \\
\text { 1. Perencanaan alokasi dana usaha untuk efisiensi } \\
\text { biaya }\left(\mathrm{W}_{4}, \mathrm{~W}_{8}, \mathrm{~T}_{6}, \mathrm{~T}_{7}\right)\end{array}$ \\
\hline
\end{tabular}

Gambar 3. Matriks SWOT pada Unit Bisnis Salamah Aqiqah

Dalam penelitian ini, satu dari empat formulasi strategi yang dipilih, yaitu kombinasi strategi W-O dilihat dari visi perusahaan. Perusahaan belum optimal mengembangkan usaha di bidang digital marketing, khususnya mengelola website dan juga untuk mengurangi kelemahan perusahaan dalam digital marketing. Strategi yang dipilih bertujuan untuk memanfaatkan peluang pengguna internet yang semakin tinggi dan gaya hidup praktis, dengan meminimalisasi kelemahan perusahaan karena belum optimalnya pemanfaatan penggunaan website sebagai sarana penting dalam digital marketing.

\section{Perencanaan Business Model Canvas Ide Bisnis}

Perencaaan business model canvas untuk ide bisnis tersebut dijabarkan sebagai berikut. Pertama, terkait customer segments untuk unit bisnis Salamah Aqiqah adalah untuk konsumen khusus wilayah Jabodetabek. Setelah mengoptimalkan website, Salamah Aqiqah memiliki segmen pelanggan baru yang cakupannya lebih luas yaitu pengguna internet dari berbagai wilayah utamanya Pulau Jawa. Menurut infografis dari Asosiasi Penyelenggara Jasa Internet Indonesia, pada tahun 2018 kontribusi tertinggi pengguna internet per wilayah dari seluruh pengguna internet adalah Pulau jawa dengan jumlah $55,7 \%$.

Kedua, value proposition atau proposisi nilai yang diberikan dalam ide pengembangan bisnis ini adalah edukasi dan informasi serta kemudahan akses informasi. Edukasi dan informasi, Salamah Aqiqah dapat memberikan informasi dan edukasi melalui website. Informasi yang diberikan dapat berupa informasi produk secara detail/katalog produk, promosi, dan lainnya, sedangkan edukasi dapat berupa wawasan seputar aqiqah, parenting dan lainnya dalam bentuk artikel di website. Kemudahan akses informasi menjadi hal penting dalam pelayanan melalui pemasaran digital. Salamah Aqiqah memberikan kemudahan akses bagi calon konsumen di website dengan meletakan ikon media sosial, seperti Instagram, Facebook dan Youtube. Selain itu, dicantumkan juga call center yang terhubung otomatis 
Ayutyas Sayekti: Optimalisasi Website Unit...

dengan WhatsApp agar konsumen mudah dalam mencari informasi secara langsung pada pihak perusahaan.

Ketiga, terkait saluran (channels) ada model bisnis sebelum pengembangan saluran tidak langsung diantaranya adalah agent marketing. Akibat adanya wabah Covid-19 juga agent marketing mungkin tidak dibutuhkan lagi, karena pelanggan dapat memesan secara langsung kepada perusahaan melalui internet tanpa adanya perantara. Pada perencanaan tersebut ada beberapa upaya tambahan yang dilakukan pada tiap fase saluran yang dibahas sebagai berikut. Upaya terkait awareness, yaitu dengan selalu aktif dan rutin memposting poster yang diunggah di Instagram yang bertautan dengan akun fanpage Faceobook Salamah Aqiqah. Penerapan SEO dilakukan dengan melakukan riset kata kunci, on page optimization, off page optimization dan analisis data. Dalam pengembangan bisnis sudah menerapkan SEO pada website Salamah Aqiqah. Upaya yang dilakukan adalah dengan mengatur komponen-komponen yang menjadi kriteria keberhasilan SEO, dari riset kata kunci, on page optimization, off page optimization dan analisis data. Setelah menerapkan SEO selama kurang lebih dua pekan di perusahaan, website Salamah Aqiqah menjadi peringkat keenam yang berada pada halaman pertama hasil pencarian Google. Selanjutnya, upaya evaluation yang pada model bisnis sebelumnya, pelanggan melakukan penilaian/evaluasi berbagai platform media sosial yang dimiliki salamah Aqiqah, setelah pengembangan konsumen dapat memberikan penilaian di website yang jangkauannya lebih luas karena dapat diakses oleh siapa saja dan di mana saja tanpa harus memiliki aplikasi seperti Instagram/Facebook. Upaya berikutnya adalah terkait dengan purchase yang pada model bisnis sebelumnya Salamah Aqiqah membuat pamflet yang dapat dibagikan ke berbagai platform sosial media, setelah pengembangan katalog harga tersebut dibuat menjadi price list lebih detail di website. Setelah itu adalah terkait delivery yang pada fase ini tidak ada perubahan yang signifikan dengan model bisnis sebelumnya, hanya pada proses pengiriman untuk luar Jabodetabek dikenakan biaya tambahan ongkos kirim yang disesuaikan dengan lokasi. Upaya terakhir adalah terkait after sales, konsumen dapat memberikan penilaian atas pesanannya melalui website yang terhubung dengan Google Maps. Penilaian yang baik dari konsumen terhadap Salamah Aqiqah berpengaruh kepada kepercayaan calon konsumen atas pelayanan Salamah Aqiqah.

Perencanaan business model canvas keempat adalah terkait customer relationship yang pada perencanaan pengembangan bisnis ini, direncanakan hubungan yang dibentuk dengan pengunjung adalah bentuk hubungan self service. Perusahaan tidak memiliki hubungan langsung dengan pelanggan tetapi dengan cara menyediakan artikel berisi informasi yang diperlukan bagi pelanggan untuk membantu permasalahan pelanggan. Perencanaan berikutnya adalah revenue streams yang masih seperti model bisnis sebelumnya dari penjualan aqiqah dan catering. Namun, juga didapatkan dari Google Adsense, untuk penjualan aqiqah meningkat berdasarkan proyeksi penjualan yang dilakukan. Berdasarkan data yang diperoleh, penjualan rata-rata domba untuk aqiqah mengalami kenaikan dalam kurun waktu lima tahun. Data penjualan per tahun 2015-2019 dapat dilihat pada Tabel 2.

Tabel 2. Data Penjualan Aqiqah Pada Salamah Aqiqah Tahun 2015-2019

\begin{tabular}{cc}
\hline Tahun & Jumlah Penjualan (Ekor) \\
\hline 2015 & 540 \\
2016 & 720 \\
2017 & 840 \\
2018 & 1020 \\
2019 & 1080 \\
\hline
\end{tabular}

Sumber: CV Mitra Tani Farm 2020 
Untuk menentukan proyeksi penjualan perlu mengetahui data historisnya, apabila ada data yang ada menunjukkan kecenderungan naik atau turun, proyeksinya dilakukan dengan tren, sedangkan untuk data historis yang berpola fluktuatif maka proyeksinya dilakukan dengan teknik average (Situmorang, 2007). Berikut adalah perhitungan proyeksi penjualan menurut Sitepu \& Sebayang (2019) dengan metode tren linier pada Tabel 3.

Tabel 3. Perhitungan Proyeksi Penjualan Aqiqah

\begin{tabular}{lcccccc}
\hline Tahun & $\mathbf{t}$ & $\mathbf{Y}$ & $\mathbf{t}-\mathbf{t}$ & $\mathbf{Y}-\mathbf{Y}$ & $\mathbf{( t - t )}(\mathbf{Y}-\mathbf{Y})$ & $\mathbf{( t - t )}^{\mathbf{2}}$ \\
\hline 2015 & 1 & 540 & -2 & -300 & 600 & 4 \\
2016 & 2 & 720 & -1 & -120 & 120 & 2 \\
2017 & 3 & 840 & 0 & 0 & 0 & 0 \\
2018 & 4 & 1.020 & 1 & 180 & 180 & 1 \\
2019 & 5 & 1.080 & 2 & 240 & 480 & 4 \\
\hline$\Sigma$ & 15 & 4.200 & 0 & 0 & 1.380 & 10 \\
$\Sigma$ & 3 & 840 & 0 & 0 & 276 & 2 \\
\hline
\end{tabular}

Berdasarkan hasil peramalan penjualan untuk tahun 2020 dengan menggunakan metode tren adalah sebanyak 1254 ekor domba/tahun atau 1080 ekor menjadi 1254 ekor meningkat sebesar 16\%. Besaran tersebut mempengaruhi besaran kenaikan untuk pendapatan lain seperti pendapatan untuk paket nasi boks yang meningkat juga sebesar $16 \%$. Pendapatan tambahan lain didapat dari Google Adsense. Layanan ini adalah sebuah layanan gratis dari Google untuk pemilik website yang ingin mendapatkan tambahan pendapatan dari berapa banyak klik untuk iklan yang dipasang di website. Sebelum memasang Google Adsense perusahaan perlu melakukan registrasi melalui website resmi Google Adsense. Arus pendapatan pada pengembangan bisnis ini diasumsikan pendapatan yang didapatkan dari Google Adsense adalah sebesar Rp7.300.000,00. Asumsi tersebut berdasarkan jumlah $\mathrm{klik} /$ traffic website yang didapat yaitu rata-rata sebanyak satu klik dalam sehari, untuk itu penulis mengasumsikan jumlah klik dalam setahun adalah 365 klik dengan harga Rp20.000,00/klik.

Kelima, key resources dimana penerapan SEO dibutuhkan perlengkapan komputer/laptop sebanyak satu unit untuk mendukung keberhasilan penerapan SEO dan seorang SEO specialist. Untuk perekrutan SEO specialist perusahaan harus menentukan kualifikasi karyawan yang relevan dengan tujuan perusahaan. Pada pengembangan bisnis ini dilakukan otimalisasi website pada unit bisnis Salamah Aqiqah dengan tujuan website Salamah Aqiqah dapat berada pada peringkat satu hasil pencarian dan dapat meningkatkan pangsa pasar perusahaan.

Keenam, key activities untuk menjangkau segmentasi konsumen lebih luas, kegiatan utama yang dilakukan adalah melayani konsumen melalui website, proses yang dipilih penulis untuk optimalisasi website yaitu dengan melakukan penerapan SEO (Search Engine Optimization). Keuntungan dari SEO adalah membantu meningkatkan pangsa pasar, meningkatkan ekuitas merek pemasar, diikuti oleh faktor-faktor lain, yaitu kesadaran produk, persuasi pembelian, dan wawasan konsumen. Melihat manfaat tersebut CV Mitra Tani Farm memberi perhatian khusus pada SEO karena dapat memiliki efek jangka panjang pada beberapa variabel pemasaran. Skema proses SEO yang dilakukan adalah melakukan optimasi pada website, dilakukan redesign website pada Salamah Aqiqah. Dalam melakukan optimasi website hal pertama yang harus dilakukan adalah riset kata kunci (research keyword). Output dari keyword research adalah list keywords yang relevan dengan bisnis Salamah Aqiqah serta average monthly search volume-nya. On page optimization adalah faktor-faktor yang menentukan teroptimasi atau tidaknya website terhadap mesin pencari dilihat dari dalam website-nya sendiri. 
Perencanaan ketujuh adalah key partners yang merupakan individu atau organisasi di luar perusahaan yang membantu menjalankan model bisnis yang telah dibuat agar berjalan sesuai tujuan perusahaan. Pada perencanaan ide bisnis ini key partners yang dibutuhkan adalah sebuah jasa yang membantu dalam maintenance website, diperlukan kerjasama dengan website developer untuk perencanaan awal sesuai dengan kebutuhan unit bisnis Salamah Aqiqah.

Perencanaan kedelapan adalah cost structure untuk biaya tambahan berupa biaya manitenance website dengan tambahan biaya untuk gaji SEO Specialist, serta tambahan biaya untuk satu unit komputer juga penambahan biaya variabel karena adanya peningkatan penjualan. Tingkat penjualan aqiqah meningkat sebesar $16 \%$ bedasarkan hitungan peramalan penjualan menggunakan metode trend linier. Beberapa komponen yang mengalami perubahan antara lain biaya untuk membeli bahan-bahan paket nasi boks, seperti beras organik, daging ayam, bumbu dapur, sayuran, minyak goreng, dan lainnya. Biaya untuk aqiqah dengan kemasan kaleng yang mengalami kenaikan adalah biaya untuk kemasan kaleng. Biaya investasi mengalami penambahan satu unit komputer karena perusahaan tidak memiliki alat komputer lebih untuk digunakan karyawan baru. Biaya tetap mengalami kenaikan yaitu dengan penambahan gaji untuk SEO specialist.

Perencanaan terakhir adalah perencanaan finansial dalam pengembangan bisnis ini menggunakan analisis laba rugi sebelum dan sesudah implementasi. Adapun asumsi yang digunakan dalam perencanaan finansial pengembangan bisnis ini adalah sebagai berikut: (1) proyeksi analisis laba rugi dibuat dalam satu tahun; (2) peningkatan penjualan sebesar $16 \%$ berdasarkan peramalan penjualan menggunakan metode trend linier; (3) penambahan pendapatan dari Google Adsense sebanyak Rp20.000.000,00 berdasarkan asumsi dalam satu tahun terdapat 365 klik dengan asumsi satu klik iklan seharga Rp20.000,00; (4) pajak penghasilan 0,5\% sesuai dengan Peraturan Pemerintah (PP) Nomor 23 Tahun 2018 tentang PPh atas Penghasilan dari Usaha yang Diterima atau Diperoleh WP yang Memiliki Peredaran Bruto Tertentu.

\begin{tabular}{|c|c|c|c|c|}
\hline \multirow{3}{*}{\begin{tabular}{|l}
\multicolumn{1}{c}{ Key Partners } \\
- Pemasok bahan baku \\
(pemeliharaan hewan \\
ternak, aqiqah dan \\
catering) \\
- Pemasok buku risalah \\
- Pemasok kaleng \\
- Website Developer: \\
Riung Code
\end{tabular}} & Key Activities & \multirow{3}{*}{$\begin{array}{l}\text { Value Preposition } \\
\text { - Hewan aqiqah } \\
\text { berkualitas baik } \\
\text { - Kemudahan akses } \\
\text { informasi } \\
\text { - Edukatif dan informatif; } \\
\text { artikel di website } \\
\text { - Produksi kalengan } \\
\text { - Free ongkir Jabodetabek } \\
\text { - Gratis video } \\
\text { dokumentasi dan buku } \\
\text { risalah aqiqah } \\
\text { - Fleksibel }\end{array}$} & Customer Relationship & \multirow{3}{*}{$\begin{array}{l}\text { Customer Segment } \\
\text { - Segmented: Konsumen } \\
\text { wilayah Jabodetabek: } \\
\text { keluarga muslim dan } \\
\text { masyarakat atau } \\
\text { organisasi yang } \\
\text { membutuhkan jasa } \\
\text { aqiqah dan catering } \\
\text { dengan gaya hidup } \\
\text { praktis } \\
\text { - Konsumen luar } \\
\text { Jabodetabek }\end{array}$} \\
\hline & $\begin{array}{l}\text { - Produksi: aqiqah dan } \\
\text { catering } \\
\text { - Pemasaran } \\
\text { - Penerapan SEO }\end{array}$ & & $\begin{array}{l}\text { - Pelayanan ramah } \\
\text { - Respon cepat } \\
\text { - Layanan customer service } 24 \\
\text { jam } \\
\text { - Voucher potongan aqiqah } \\
\text { dan qurban sebesar } \\
\text { Rp50.000,00 } \\
\text { - Self service: artikel di } \\
\text { website }\end{array}$ & \\
\hline & \begin{tabular}{l}
\multicolumn{1}{c}{ Key Resources } \\
- Sumber daya fisik; 1 unit \\
komputer \\
- Sumber daya manusia; 1 \\
orang SEO Specialist \\
- Sumber daya finansial
\end{tabular} & & \begin{tabular}{l}
\multicolumn{1}{c}{ Channels } \\
- Word of mouth, buku risalah \\
- Website \\
- Media sosial (Instagram, \\
Facebook, Youtube, \\
WhatsApp)
\end{tabular} & \\
\hline \multirow{2}{*}{\multicolumn{2}{|c|}{$\begin{array}{l}\text { - } \quad \text { Biaya investasi; } \\
\text { - } \quad \text { Biaya tetap; gaji } \\
\text { - Biaya variabel }\end{array}$}} & \multicolumn{3}{|c|}{ Revenue Streams } \\
\hline & & \multicolumn{3}{|c|}{$\begin{array}{l}\text { - Penjualan aqiqah dan catering } \\
\text { - Google Adsense }\end{array}$} \\
\hline
\end{tabular}

Gambar 4 Business Model Canvas Unit Bisnis Salamah Aqiqah setelah Pengembangan 
Analisis laporan laba rugi perusahaan sebelum dan sesudah penerapan dapat dilihat di Tabel 4.

Tabel 4. Analisis laba rugi dan $\mathrm{R} / \mathrm{C}$ ratio

\begin{tabular}{lrr}
\hline \multicolumn{1}{c}{ Komponen } & \multicolumn{1}{c}{ Sebelum } & \multicolumn{1}{c}{ Sesudah } \\
\hline Penjualan & & \\
Paket Aqiqah & $\mathrm{Rp} 1.823 .400 .000,00$ & $\mathrm{Rp} 2.126 .340 .000,00$ \\
Paket Nasi Boks & $\mathrm{Rp} 852.000 .000,00$ & $\mathrm{Rp} 1.152 .000 .000,00$ \\
\hline Google Adsense & & $\mathrm{Rp} 7.300 .000,00$ \\
Biaya Produksi & $\mathrm{Rp} 199.568 .680,00$ & $\mathrm{Rp} 243.569 .898,00$ \\
Biaya Tetap & $\mathrm{Rp2} .265 .634 .150,00$ & $\mathrm{Rp} 2.715 .934 .476,00$ \\
Biaya Variabel & $\mathrm{Rp} 2.465 .202 .830,00$ & $\mathrm{Rp} 2.959 .504 .374,00$ \\
Total Biaya Produksi & $\mathrm{Rp} 210.197 .170 .00$ & $\mathrm{Rp} 326.135 .626 .00$ \\
Laba Bersih & $\mathrm{Rp} 1.050 .986,00$ & $\mathrm{Rp} 1.630 .678,00$ \\
Pajak Penghasilan 0.5\% & $\mathrm{Rp} \mathrm{209.146.185,00}$ & $\mathrm{Rp} \mathrm{324.504.948,00}$ \\
Laba Bersih & $\underline{1,09}$ & 1,11 \\
R/C ratio & &
\end{tabular}

Berdasarkan Tabel 4 terlihat laba bersih perusahaan mengalami peningkatan sebesar $\mathrm{Rp} 115.358 .7633,00$ dan $\mathrm{R} / \mathrm{C}$ ratio meningkat juga sebesar 0,02 . R/C ratio yang didapatkan setelah pengembangan adalah sebesar 1,11 yang berarti setiap $\mathrm{Rp} 1,00$ yang dikeluarkan menghasilkan pendapatan sebesar Rp1,11,00. Berdasarkan kriteria kelayakan usaha, dengan nilai laba bersih bernilai positif dan $\mathrm{R} / \mathrm{C}$ ratio lebih dari 1 (>1) maka usaha itu dinilai layak untuk dijalankan.

\section{Pembahasan Hasil Penelitian}

Rangkuti (2015) mengatakan alat yang membantu dalam menyusun faktor-faktor strategis perusahaan adalah matriks SWOT. Matriks ini dapat menggambarkan secara jelas bagaimana peluang dan ancaman eksternal yang dihadapi perusahaan dapat disesuaikan dengan kekuatan dan kelemahan yang dimiliki perusahaan. Matriks SWOT dapat menghasilkan empat alternatif strategi. Dalam penelitian ini yang digunakan adalah strategi W-O atau weakness dan opportunities. Strategi ini diterapkan berdasarkan pemanfaatan peluang yang ada dengan cara meminimalisasi kelemahan yang ada.

Berdasarkan business model canvas yang sudah dipetakan untuk mengidentifikasi sembilan elemen pada model unit bisnis Salamah Aqiqah dan katering. Penerapan model bisnis pada business model canvas ini untuk mendapatkan model bisnis baru yang sesuai dengan keinginan pelanggan dan adanya evaluasi bisnis (Tanev dkk., 2016). Target pasar yang dimiliki sudah jelas yaitu keluarga muslim yang membutuhkan jasa aqiqah dan masyarakat/organisasi yang membutuhkan jasa catering dengan gaya hidup praktis, sudah sangat jelas sikap yang harus diambil dan bagaimana perusahaan seharusnya megambil peluang yang ada terutama di masa pandemic COVID-19 dan untuk menghadapi era new normal. Konsep dasar business model canvas adalah menyederhanakan bentuk model bisnis yang sebelumnya terdiri dari berlembar-lembar kertas dengan pemaparan yang sangat panjang, kini dibuat menjadi lebih ringkas (Oktora dkk., 2018).

Berdasarkan hasil value proposition dan customer relationship dibutuhkan pengemasan dan promosi yang baik untuk konsumen yang potensial. Salamah Aqiqah dapat memberikan informasi dan edukasi melalui website serta kemudahan akses informasi menjadi hal penting dalam pelayanan. Khususnya di era e-commerce dimana semua lini usaha terdisrupsi sehingga dibutuhkan strategi yang mengedepankan model bisnis yang berbeda dan sustainable (Umar dkk., 2018). Berdasarkan fase terdiri dari awareness, evaluation, purchase, delivery dan after sales. Upaya yang dilakukan adalah dengan 
Ayutyas Sayekti: Optimalisasi Website Unit...

mengatur komponen- komponen yang menjadi kriteria keberhasilan SEO mulai dari riset kata kunci, on page optimization, off page optimization dan analisis data. Setelah menerapkan SEO selama kurang lebih 2 minggu di perusahaan, website Salamah Aqiqah menjadi peringkat keenam yang berada pada halaman pertama hasil pencarian Google. Penggunaan platform media sosial untuk menarik pelanggan. Dengan menggunakan media sosial, para pelaku bisnis dapat membangun hubungan yang harmonis dengan konsumen (Umami \& Darma, 2021).

Dalam perencanaan sumber daya tidak lepas dari sumber daya manusia yang dibutuhkan untuk mengoperasikan SEO dan secara cakap didukung dengan teknologi yang baik. Keuntungan paling menonjol dari SEO yang diidentifikasi dari penelitian Bhandari \& Bansal (2018) membantu meningkatkan pangsa pasar, meningkatkan ekuitas merek pemasar. Optimalisasi di luar halaman website menunujukkan Semakin banyak dan semakin tinggi kualitas linknya, maka semakin baik pula peringkat website tersebut. Inilah mengapa link dari website lain (backlink) memegang peranan penting dalam SEO. Setelah semua upaya penerapan SEO dilakukan, alangkah baiknya perusahaan melakukan monitoring atau analisis data terhadap website yang dimiliki. Website juga perlu di maintenance untuk kebutuhan unit bisnis dan keberlangsungan usaha. Pelaku usaha harus mengikuti perkembangan zaman agar tidak ketinggalan salah satunya dengan melakukan promosi melalui social media marketing (Zhu \& Gao, 2019). Hal yang tidak kalah penting dalam 9 elemen adalah perencanaan finansial menggunakan analisis laba rugi dan $\mathrm{R} / \mathrm{c}$ ratio (revenue cost ratio), terdapat peningkatan sebelum adanya optimalisasi dengan nilai 1,09 dan sesudah adanya optimalisasi menjadi 1,11 yang menyatakan bahwa bisnis secara ekonomis itu layak untuk diusahakan dan dikembangkan. Berdasarkan (Ely \& Darwanto, 2014) nilai R/c usaha lebih besar dari satu (R/C $>1)$ maka usaha layak untuk dikembangkan begitu juga sebaliknya.

\section{KESIMPULAN}

Ide pengembangan bisnis optimalisasi website pada unit bisnis Salamah Aqiqah dengan penerapan SEO yang dapat meningkatkan peringkat website pada mesin pencari, diperoleh dari analisis business model canvas dan analisis SWOT. Hasil analisis tersebut mengubah komponen elemen model bisnis, seperti adanya pengurangan agent marketing pada elemen channels, dan adanya penambahan komponen pada elemen customer segment, value proposition, customer relationships, key activities, key resources, key partners, revenue streams dan cost structure. Berdasarkan hasil analisis nonfinansial sembilan elemen model bisnis pada pengembangan bisnis ini layak dilakukan. Berdasarkan analisis finansial yang dilakukan dengan analisis laporan laba rugi,nilai laba yang di dapatkan sebesar Rp324.504.948,00 berarti lebih dari nol maka laba positif, dengan perhitungan $\mathrm{R} / \mathrm{C}$ ratio sebesar 1,11 mempunyai arti bahwa setiap Rp1,00 yang dikeluarkan menghasilkan pendapatan sebesar Rp1,11,00 hasil tersebut lebih dari satu (>1) maka bisnis layak untuk dijalankan.

\section{DAFTAR PUSTAKA}

Asosiasi Penyelenggara Jasa Internet Indonesia. (2018). Penetrasi \& Profil Perilaku Pengguna Internet Indonesia. https://apjii.or.id/survei2019x/download/rLCZIznRy8GeBPvpt9usilKW7XED6q

Bhandari, R. S., Bansal, A. (2018). Impact Of Search Engine Optimization As A Marketing Tool. Jindal Journal of Business Research, 7(1), 24-36. https://doi.org/10.1177/2278682117754016

Bilgin, Y. (2018). The Effect Of Social Media Marketing Activities On Brand Awareness, Brand Image And Brand Loyalty. Business \& Management Studies: An International Journal, 6(1), 128148. https://doi.org/10.15295/bmij.v6i1.229

Cizmeci, F., \& Ercan, T. (2015). The effect of digital marketing communication tools to create brand awareness by housing companies. Megaron, 10(2), 149-161. http://dx.doi.org/10.5505/megaron.2015.73745 
Ely, A., \& Darwanto, D. H. (2014). Feasibility Analysis and Development Strategy Business of Seaweed Cultivation in Seram Bagian Barat Regency. Jurnal Agro Ekonomi, 25(2), 169-177.

Fatimah, S. (2017). Strategi Komunikasi Pemasaran E-Commerce Melalui Website KLIKHOTEL.com. Jurnal Common, 1(2), 89-100. https://doi.org/ 10.34010/COMMON.V112.572.

Fawaid, A. (2017). Pengaruh digital marketing system, terhadap daya saing penjualan susu kambing Etawa. Iqtishadia: Jurnal Ekonomi dan Perbankan Syariah, 4(1), 104-119. https://doi.org/10. 19105/iqtis hadia.v4i1.1134

Firdaaus, R. (2020, April 10). Penggunaan Internet di Indonesia Saat Ini Mencapai 175 Juta. https://www.scribd.com/document/492632168/Pengguna-internet-di-Indonesia-saat-inimencapai-175

Handika, M. R., \& Darma, G. S. (2018). Strategi pemasaran bisnis kuliner menggunakan influencer melalui media sosial instagram. Manajemen dan Bisnis, 15(2), 192-203. https://doi.org/ $10.38043 /$ jmb.v15i2.601

Kasmir, \& Jakfar. (2003). Studi Kelayakan Bisnis. Jakarta: Kencana Prenada Media Group.

Nurmalina, R., Yulianti, C., Fitri, Utami, A. D., Sari, R. M., Risenasari, H., Siwang, R. S., Khotimah, H., Rosiana, N., Rachman, A., Hasibuan, M. (2015). Pemasaran: Konsep dan Aplikasi. Bogor: IPB Press.

Oktora, K., Firmansyah, D, Anita, I. R. (2021). Strategi Pengembangan Badan Usaha Milik (BUM) Desa Menuju Kawasan Bisnis Pariwisata Trepadu di Desa Karang Tengah. JIMFE (Jurnal Ilmiah Manajemen Fakultas Ekonomi), 7(1), 109-121.

Osterwalder, A. \& Pigneur, Y. (2010). Business Model Generation. Hoboken: Printed in the United States of America.

Rangkuti, F. (2015). Analisis SWOT: Teknik Membedah Kasus Bisnis. Jakarta: PT Gramedia Pustaka Utama.

Sitepu, K.R., Sebayang, B. V. (2019). Metode Kuantitatif untuk Manajemen. Bogor: CV Sinar Jaya.

Situmorang, H. S. (2007). Studi Kelayakan Bisnis: Buku 1. Medan: USU Press.

Statista Digital Market Outlook For Fintech. 2020. Figures Use Full-Year Values for 2019, with Comparisons to Equivalent 2018 Data. https://www.statista.com/outlook/digital-markets

Stokes, R. (2013). E-Marketing: The Essential Guide to Marketing in A Digital World. South Africa: Quirk eMarketing [Pty] Ltd.

Tanev, S., Rasmussen, E. S., \& Riber Hansen, K. (2016). Business Plan Basics for Engineers. Start-Up Creation: The Smart Eco-efficient Built Environment, 66, 21-37. https://doi.org/10.1016/B978-008-100546-0.00002-9

Umami, Z., \& Darma, G. S. (2021). Digital Marketing: Engaging Consumers with Smart Digital Marekting Content. Jurnal Manajemen dan Kewirausahaan, 23(2), 94-103.

Umar, A., Sasongko, A. H., Aguzman, G., \& Sugiharto. (2018). Business Model Canvas as A Solution For Competing Strategy of Small Business in Indonesia. International Journal of Entrepreneurship, 22(1), 4675.

Zhu, G., \& Gao, X. (2019). Precision Retail Marketing Strategy Based On Digital Marketing Model. Science Journal of Business and Management, 7(1), 33-37. http://dx.doi.org/10.11648/j.sjbm.20190 701.15 
